\title{
Role of Computer Applications in Science and Engineering
}

\author{
Dr. Daruri Venugopal
}

Professor, Department of Mathematics, OPJS University, Churu, Rajasthan, India.

\section{To Cite this Article}

Dr. Daruri Venugopal, "Role of Computer Applications in Science and Engineering”, International Journal for Modern Trends in Science and Technology, 6(8S): 82-88, 2020.

\section{Article Info}

Received on 16-July-2020, Revised on 15-August-2020, Accepted on 25-August-2020, Published on 28-August-2020.

\section{ABSTRACT}

A computer is a programmable Scientific machine. It is purely based on set of instructions in a well defined manner. It can execute a prerecorded list of instructions as a program. Personal Computers, Workstation, Minicomputer, Mainframe, Supercomputer are the different computer models. This Research manuscript provides the major role of computers in scientific research. Provides the role of computers in the film industry, Role of Computers in art, Role of computes in Advertising Industry. It also explains the involvement in the sector of Engineering productivity, Telemedicine, Medical care and Musicians, Hospitals, Military Organizations. It explains the features of prototyping, Product Data Management, Project Management and also CAD/CAM Application System. Computers are playing vital role in house hold.If Considered the role of Computers in house hold sector the household appliances and gadgets have computers in them. Explains the concept of Applications of Computes in Business Sector, Project management System for smooth functioning of the respective Industrial sector. Major components of computers, characteristics of computers in different sectors, and the storage capability of a computer also explained in this manuscript.

KEYWORDS: Advertising Industry, Scientific, Workstation, mainframe, prototyping, Telemedicine.Musicians.

\section{INTRODUCTION}

Computers require Central Processing Unit, Memory, Input device, Output device, Mass Storage device, etc., CPU is the heart of the computer, the component that actually executes instructions. Storage and memory enables a machine or a computer system to store data and programs. Usually key board or mouse the input device is the conduct through which data and instructions enter a computer system. A display, screen, printer etc., are the devices that lets us what the computer has accomplished. Data
Storage device, hard disks allows a computer to permanently retain large amounts of data. All the computers have certain common characteristics irrespective of their configuration. They can be programmed to do complex, and monotonous result oriented tasks.Accuracy, Versatility, Automation, Storage, Speed, Word count are few of the characteristics of Computer. The computers are designed as amazing machine. In business, Computers have become very crucial that we cannot even think how we will be able to survive Without them. 
Now days computers are used for everything from diagnosing illnesses to monitoring patients during surgery and controlling permanently.Drafting tables, architect designing a product can be far more productive with a computer than with pencil and paper. Musicians and singers have teamed up with computers to create an amazing range of instruments and sounds simply by playing a Key Board.

Telecommunication signaling system refers in computer prospectus as data transmission from voice to video. Communication is the transmission of data from one computer to other computer and * similarly from one place to another place. A geographic information system is a computer based tool for location sketch and analyzing things that exist on earth and GIS technology.

\section{COMPUTERS IN SCIENCE}

Scientists use computers to develop technology to collect and test data, and to exchange information electronically with colleagues around the world. Scientists can use powerful and advance technology based computers to generate detailed studies of how earthquakes affect buildings, and how pollution effects.

* Using advanced level configuration computers and sophisticated software, scientists can model complex molecules and can experiment with compounds that do not yet exist.

* In every field of Scientific research, we use computers to store, analyze and manipulate * information. People from different parts of country can work on same project.

* In information technology Computers help in collaborative research and also information sharing process. It would be impossible to explore outer space without the help of computers.In several sectors for quick process and easiest * programmed process majority of people use familiar kind of computer that is microcomputer.

* Personal computers ran comparatively easy to use applications software such as the word processors, $*$ spreadsheets etc.

* Personal Digital Assistants (PDAs) includes many features and communication capabilities in a very small package. Businessman, Executives use these machines for their day to day activities

\section{COMPUTERS IN ENGINEERING}

In global economy, it is absolutely necessary for an organization to keep costs as low as possible to remain competitive. Since design production and manufacturing consume so much of manufacturing company budget, great savings are being made by automating these procedures as much as possible. Computer Aided Design is a popular tool in Engineering.

CAD systems are computer programs packages for workstation hardware and software that allows the user to draw and easily modify product designs on a computer screen. Majority of CAD Systems can store the design characteristics of existing products.

The CAD System decides and confirms whether the company is already using an identical of sufficiently similar gear or not.

In Automatic evaluation of specifications process one of the most time consuming aspects of design for highly technical products is calculating whether or not product specifications, such as strength, heat resistance or aerodynamic drag are satisfied. Electronic Data Interchange - which is well known in information technology as EDI is one of the computer to exchange of business documents in a standard format. These formats and outcome results look much like standard forms though highly structured technology.

In general widely used format is for purchase orders which consists of an outer digital envelopemodel with the addresses bar of both the sender and receiver. Inside the digital envelope, a series of structured codesstates the part number, cost, tax information, shipment methods, and bills.

\section{IV.COMPUTERS IN MOVIES}

In real life situations and in industrial sectors computers help in improving productivity by automating time consuming, repetitive and monotonous processes.

Movies in generalconsists many visual tricks and treats that could never be accomplished without the involvement of computers. The computers can create outer space, alien characters, and extinct 
animals and so on without the need of creating their physical appearance/availability.

* Anybody who has seen science fiction movies the special effects in movies like cartoons, will know the importance of computes in the film industry. With the aid of graphics and animation packages the special effects technicians can create the illusion of locomotive flying through the air transforming into a human being and so on.

* The performing artists might even use computers to control the images and sounds of the performance itself. As a advanced technology now animator can create in a short time any special effects, which used to take days with hand-drawing techniques. In film industry Computer technology has given the ability to create special effects with $3 \mathrm{D}$ animations that were not possible in older days. Now computes are used in almost all phases of movie making may it be writing scripts, creating special effects, editing, adding sound effects and * other major effects.

\section{COMPUTERS IN ENTERTAINMENT}

* Computers in entertainment sector become an integral part of the entertainmentIndustries/Sectors. They are used for creating special effects in movies. Computers are used in editing movies, and also used to create full length movies with cartoon characters.

* They are also used in multimedia presentations. They help in recording and reproducing music and sound effects, composing, editing etc...

- Computers are used in Sports authority by professionals to analyze their techniques to find their strengths and weaknesses.

* Computers are used to simulate games and to identify the new strategies.

\section{COMPUTERS IN MUSIC}

The use of latest technology in the world of music today is an inescapable fact. Any musical event * that we notice goes through a technological process at some point. This can be when the piece of music is created, and when it is played.

Technology improved the musical information and communication in scope over the past few decades to a remarkable extent. Majority of songs have some sort of electronic instrumentation. The same things is in the music in TV commercials, cartoons, and popular movies. we can observe that in most of the sounds are electronic in nature.

Musical instruments have always been machines, which are valuable only in hands of people, not by themselves.

Significant developments in the history of electronic music came in 1983 year. When major electronic instruments manufactures developed a communication standard called Musical Instrumental Digital Interface.

There were a lot of problems with interfacing electronic the compatibility problems were avoided by largely ignoring how a certain instrument generates a sound.

We can identify several music composition Languages which resemble programming,instrumental languages in the sense that they provide ways to create music on a computer as Symbolic Composer, which run on different platforms like Mac, IBM PC, UNIX, and others.

In a global perspective, all musical forms can be simulated with this approach method. It is based on pure mathematical approach methods involving recursion process iteration and complex mathematics.

\section{COMPUTERS IN ADVERTISING}

There are many ways to use computers in advertising sector. We can divide them based on their role of applications and uses into two group. One of them is the use of multimedia in advertising sector and promoting products and the other is the utilization of the available internet sources. Advertising has been one of the major key factors of growth and success in entrepreneurship or in any businesssector.

We can identify that all favorable types of promoting different products had been used. In reality, only at the beginning of the decade computer really become considerably inexpensive, small in size, and freely available to many people. 
* Sound and video make computer presentations Animation, computer graphics, attracting to all people. We can observe that different applications of multimedia are applied everywhere from a desktop presentations in a small travel agency to any other multimedia exhibitions on computer presentations. Modern computers are very user * friendly. Many applications do not require all people.

\section{COMPUTERS IN ART}

In Art sector we can classify computers in two patterns as Computer image processing and computer graphics. Computer graphics deals with the most fundamental aspects of image creation while image processing transforms existing images into a desired end product. A computer and an artist have a similar and relationship, through the nature of the relationship has not yet been fully accepted.Few of the artists embrace Instrumental technology not only as a new tool but also as a new fine arts course, capable of transforming art from visual experience to full emotional interaction.

* If we observe in a global fact that the computer revolution has touched every area of industrial sectors, including the art world. In technology based scientific aspects the first electronic art combination of experiments in artificial intelligence, and computational matrices. Earlier days the computers were not user friendly, typical understandable programmed machines and there was no effective means of output.

* Computer graphics is widely in all areas of Sectors used in computer animation due to its precise and powerful data manipulation algorithms. People involved in computer graphics need programming knowledge as well as understanding its perspective, software skills, such as shading hidden line, hidden surface removal, shadowing, ray-tracing, anti-aliasing as well as more traditional aspects of image creation.

* Image processing on the other hand takes advantage of powerful easy to use software packages like Corel Draw, Microsoft Photo Draw, Painter, Adobe Photoshop and others.

* It is now accepted that the new media "multimedia, electronic art" or simple computer art is rapidly changing the way engage ourselves with issues of a gateway to limitless forms of self-expression.
The technology is changing day by day andproviding the latest technology outputs in a new form of self-expression. We can observe that the viewer is no longer forced to absorb an image.

Interactive art allows the viewer to be the director and to experience the nature of work in his allotted time.

Each medium offers the artist latest application tools, technology based new methods which lead to works unique to that medium. Just as the camera allowed the photographer to capture one particular situation.

New media technical applications allows the artist to invoke situational emotions unreachable with a brush. Cyberspace will bring art to every home across social geographical and political barriers.

\section{COMPUTERS IN MEDICINE}

Computers play aimportant role and act accordingly in patient monitoring and automated drug administration. In hospitals, bedside clinical information and other data sources systems collect vital sign measurements directly from patient monitors and automate the charting process.

The technology based latest drug administration systems automate the process of administrating medicines to all levels of patients. It is declared as a universal development fact as Computers are revolutionizing the medical field.

Computers are used in the medical field for performing different important treatment related tasks. In medicine computers are used for everyone from diagnosing illnesses and monitoring patients to controlling movements of robotic surgical assistants. It provides the complete case history of different patients based on the given serial number, Name of the patient, Case number date of admit, and all sort of treatment details in the patient Observation sheet and provides the time to time schedules for monitoring the patients.

* The advantage of the electronic patients records over the paper counterparts is that the electronic documents can be searched for specific keywords, can be sent via email to other doctors for second 
opinions can be stored and retrieved more effectively, and so on.

* The computerized systems automate the billing, * and other administrative processes, thus freeing the doctors and medical staff,

so that they can spend more time on practicing medicine.

* The latest developments in digital and imaging technology have helped in better

* and easy diagnosis as the images and outputs produced by the latest equipment's are capable of delivering more information. Advancements in the field of biomedical engineering results in the development of laboratory and medical equipment's that are better and more accurate. Several innovative medical, bio-medical, applications are used, as a special purpose of treatments in computers.

* Considering the Treatment process in medical grounds - pacemakers are computers that operate within the human body to help it function better. Similarly cochlear implant, a special kind of hearing aid that allows profoundly deaf people to hear. Part of the device performs as a small computer that transforms sound into electrical * impulses, which are then transmitted to the brain by a device implanted in the inner ear.

* Magnetic resonance imaging that is MRI uses radio waves and a strong magnetic field to scan a patient's body. A commuter assembles this information into a picture that shows internal organs and certain types of diseased tissue.

* Another use of computers in the hospital is for automated imaging techniques, which produce a fully dimensional picture with much more detail and less risk than the standard X-ray films. The first widespread type of imaging to be used was computerized axial tomography scans.

* Video conferencing, live video presentations and other related technologies help in the collaboration of doctors from the different parts of the world. Latest technical developments in telemedicine have made the life of patients easier and enable them to get high quality medical care and safety precautions irrespective of their physical location.
Telemedicine uses updated technology to deliver medical services at all levels of treatments to the point of requirements.

- Artificial intelligence principles helps to these programs attempt to anticipate what the user is typing.

* Once the user enters the first character of a word, the program suggests possibilities. With each new character typed, the predicated list of words becomes shorter.

Once the desired word appears, the user can select it, instead of typing the remaining characters.

* In medical levels Voice recognition systems allow users with many kinds of physical disabilities to speak, create commands to their computers. They many provide hundreds of preprogrammed selections for various types of applications such as word processing, desktop publishing, and graphics.

People with visual impairments can use large screen monitors, and can apply high contrast labels to their keys for easy visualization. Optical character Recognition software can translate printed information into computer-generated speech or braille, and braille transitions can send output to special printers that emboss braille characters on paper.

To help public with everyday tasks, there are voice controlled, on computer screen telephones that perform all the functions of a standard telephone, and others as well.

People who cannot pick up and dial a regular telephone can use any pointing device such as a mouse, headset, or joystick to operate an on-screen telephone.

There are many options in computer related industries to assist people who have disabilities. We can identify many options in every sector as above. 


\section{COMPUTERS IN PROJECT MANAGEMENT}

In Majority of Organization sectors when projects * from marketing In Organization sectors when projects from marketing campaigns to construction projects are undertaken, keeping track of all the tasks is a big job and that is what project management programs have been developed to do it in successful manner.

* One concept they use is the critical path; the series of tasks that must follow one another in order and cannot be overlapped or begun until the previous one is completed. Any delays in the tasks on the path delay the entire project.

* Tasks no on the critical path like paving the * driveway do not affect the projects only by changing the dates on the critical path.

\section{XI.COMPUTERS IN EDUCATION AND TRAINING}

* An education is not complete without a strong and well disciplined cultural component. In information age, communication is a survival skill. Isolated factory workers and others vanishing from the workplace.

* With rapidly clanging job descriptions an d job markets it is unreason unable to assume that students can be trained once for lifelong jobs.

* These facts suggest that we can longer afford to think of education as a one-time vaccination against illiteracy.

* In the information age, learning must be lifelong processes. To prepare students for a lifetime of leering, schools must teach students more than facts; they must make sure students learn how to think and learn.

Many academicians strongly believe that computers and information technology are major and essential parts of these changes. In all over the world in educational institutions computers are become basic requirements.

* Students and faculty members are using these computers in a variety of ways to learn.

- Students can learn individually in their own place. Teachers/faculty members can spend their time working one to one with students an important activity that is almost impossible in typical presentation and discussion classrooms.

Computer Aided Instructor Software can turn practice into an entertaining game. It motivates students to practice arithmetic, spelling, touch typing, keyboard and other skills in their learning process.

* Computer Aider Instructions can help timed children become comfortable with computers as well as with the subject matter being taught. A well designed program is infinitely patient.In several Research cases it is observed that children, disadvantaged children, and especially learning disabled students tend to respond positively to CAI.

In productivity Tools - Some Educational Institutions also provide special purpose tools for classroom use, including Laboratory sensing hardware and software that can be used to collect scientific data which is further converted to computer data is analyzed by students.

In many of the Institutions, schools, colleges, Universities teachers are using computer graphics, videodiscs, CDs and other digital media to convey information in a more dynamic form.

To maximize students involvement, some teachers/faculty put multimedia authorizing tools in the hands of students.

Instead of creating interactive topics or lessons for students, teachers allow the students to create their own multimedia presentations.

Communication technology is particularly important for students in remote locations.

* By the help of Telecommunication technology child in small town develops an interest in a narrow subject.

Distance learning also offers promise for workers whose jobs are changed or eliminated by shifting economy.

- Many displace workers cannot afford to relocate their families to college towns so that they can learn new skills. 


\section{CONCLUSION}

Using computers and advanced software, scientists can model complex molecules and can experiment with compounds that do not yet exist. The computers and latest information technology help in collaborative research aptitudesand in information sharing. In Several aspects and several sectors Computers help in improving productivity and, automating time consuming, and also monotonous processes. Now computes are used in almost all phases of movie making may it be writing scripts, creating special effects, editing, adding sound effects and other major effects. Technology improved the musical information and communication in scope over the past few decades to a remarkable extent.

Advertising of any product, scheme has been one of the key factors of growth and success in business. A scientific computer and an artist have a similar relationship, through the nature of the relationship has not yet been fully realized.

We can observe that some of the artists embrace technology not only as a new tool but also as a new fine arts.Computers are used in the medical field for performing positive outcome and quick results in a fixed task. In medicine computers are used for everyone from diagnosing illnesses and monitoring patients to controlling movements of robotic surgical assistants. In medical Grounds to help people with everyday tasks, there are voice controlled, on screen telephones that perform all the functions of a standard telephone, and others as well.

\section{ACKNOWLEDGMENT}

I Wish to show my gratitude to my Academic GruruDr.G.Manohar Reddy Garu and Dr.N.GouthamRaoGaru Management of Swamy Vivekananda Educational Trust, Hyderabad for their motivational thoughts and Support in Academics and Research Activities.

\section{REFERENCES}

[1] Peter Norton's Introduction to Computers, Mc Graw-Hill, 1997.

[2] Microcomputer Applications, Robert T.Grauer and Paul K.Sugrue, McGraw-Hill, 1987.

[3] Digital Principles and Applications, A.P.Malvino and D.P.Peach,Mc.Graw-Hill. 1986.

[4] Essential Virtual Reality Fast,Vince,Springer Verlag, 1998.

[5] Multimedia and Virtual Reality EngineeringmBrice,Newnes, 1997.
[6] Operating Systems-Desing and Implementation,A.S.Tanenbaum,Prentice Hall, 1987.

[7] The Internet Complete Reference, Harley Hahn,Osborne McGraw-Hill, 1996.

[8] The Data Warehouse Mehod,Debevoise,Prentice-Hall PTR, 1999.

[9] The Data Warehouse Lifecycle Toolkit,Kimball,John Wiley \& Sons, 1998.

[10] Computer Graphics, Donald Hearn and M.Pauline Baker, Prentice Hall, 1986.

[11] Business Data Communications David A. Stamper,Addison Wesley, 1994.

[12] Digital Electronics-Fundamental Concepts and Applications, C.E.Strangio, Prentice Hall, 1980.

[13] Digital Computer Fundamentals, T.C. Bartee, McGraw-Hill, 1985.

[14] Computers and Information Systems, M.R. Gore and J.W. Stubbe,McGraw-Hill, 1984.

[15] Computer Organization, Hamacheer,Vranesic and Zaky.Mc.Graw-Hill, 1996.

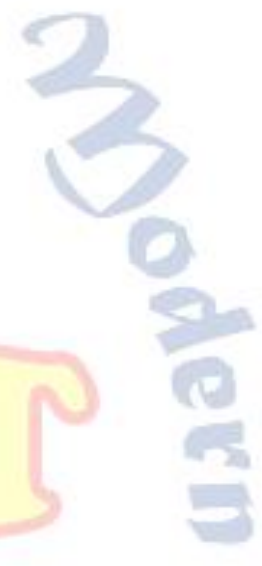

